\title{
Communicating Climate Change: Probabilistic Expressions and Concrete Events
}

\author{
SUSAN JOSLYN AND RAONI DEMNITZ \\ University of Washington, Seattle, Washington
}

(Manuscript received 5 November 2018, in final form 19 May 2019)

\begin{abstract}
Despite near unanimous agreement among climate scientists about global warming, a substantial proportion of Americans remain skeptical or unconcerned. The two experiments reported here tested communication strategies designed to increase trust in and concern about climate change. They also measured attitudes toward climate scientists. Climate predictions were systematically manipulated to include either probabilistic ( $90 \%$ predictive interval) or deterministic (mean value) projections that described either concrete (i.e., heat waves and floods) or abstract events (i.e., temperature and precipitation). The results revealed that projections that included the $90 \%$ predictive interval were considered more trustworthy than deterministic projections. In addition, in a nationally representative sample, Republicans who were informed of concrete events with predictive intervals reported greater concern and more favorable attitudes toward climate scientists than when deterministic projections were used. Overall, these findings suggest that while climate change beliefs may be rooted in partisan identity, they remain malleable, especially when targeted communication strategies are used.
\end{abstract}

\section{Introduction}

Conveying the implications of climate change, including the uncertainties involved, is one of the greatest challenges currently facing the scientific community (National Research Council 2011). There is now nearly unanimous agreement among climate scientists about the existence of climate change (Anderegg et al. 2010; Cook et al. 2013), including the effects of anthropogenic global warming already in evidence (Wuebbles et al. 2017). However, as yet, a full-scale public response has failed to materialize in the United States (Bierbaum et al. 2013; Leiserowitz et al. 2013). Although there are many possible reasons for the lack of public response, here we investigate the impact of climate communication strategies on two of them: public distrust in the information about climate change coming from the scientific community and lack of concern about the consequences of climate change.

Despite a wealth of evidence to the contrary, a full $30 \%$ of Americans are not sure that climate change is happening, and half of those are sure it is not happening (Leiserowitz et al. 2018). This suggests that some people distrust the scientific community's conclusions about global warming. Indeed, there is abundant research

\footnotetext{
Corresponding author: Susan Joslyn, susanj@uw.edu
}

highlighting the importance of trust for beliefs about complex and controversial issues such as this (Nisbet and Markowitz 2016).

Furthermore, skepticism about climate change may arise, at least in part, from the perception of lack of scientific consensus on the subject. About a third (33\%) of Americans recently reported that they believe there is "a lot of disagreement among scientists" (Marlon et al. 2013). Only $15 \%$ are aware of the actual degree of scientific consensus (by some estimates 97\%; Cook et al. 2013). This is important because there is evidence that scientific consensus is a gateway belief, increasing acceptance that climate change is happening, human caused, and a worrisome threat (van der Linden et al. 2015).

The perception of lack of consensus may stem from the considerable uncertainty regarding the extent, time scale, and consequences of climate change. In some cases, the best scientific data support a wide range of outcomes. This may contribute to the misperception that the scientific community is divided about the existence of climate change. In other words, a primary cause of distrust may be the misinterpretation of divergent information about climate outcomes as a lack of consensus among scientists about climate change per se (Ding et al. 2011; Freudenburg and Muselli 2010; Lewandowsky et al. 2013; Moser 2010). In the worst 
case, climate change described as differing possible outcomes might give rise to the perception that climate scientists are incompetent (Johnson 2003; Johnson and Slovic 1995, 1998) or deliberately manipulating the data to advance their own agenda, a fundamentally different and intrinsically less trustworthy kind of uncertainty (Oreskes and Conway 2010).

If people distrust climate projections because they think the range of outcomes indicates lack of consensus, incompetence, or ulterior motives, then providing explicit numeric uncertainty information may counteract these fears by indicating that the range is due to quantifiable uncertainty inherent in the prediction process, rather than to other less trustworthy factors (Rabinovich and Morton 2012). Indeed, there is evidence that conflicting point estimates presented as a range are considered more credible than the same values attributed to different experts (Benjamin and Budescu 2018). Thus, explicit numeric uncertainty estimates may restore the perception of credibility and competence, increasing trust. Moreover, there is some preliminary evidence, with a nonrepresentative sample, showing significantly greater trust in global average temperature increase and sea level rise described as range of values having a $90 \%$ chance of encasing the actual value than when described as a point estimate (Joslyn and LeClerc 2016). This finding is in line with recent research in a less politicized domain, suggesting that numeric uncertainty estimates increase people's trust in weather forecasts as well as lead to economically better decisions (Joslyn and LeClerc 2012; Savelli and Joslyn 2013). Importantly, these effects are not dependent background or education (Grounds and Joslyn 2018; Grounds et al. 2017), perhaps because most people intuitively understand that weather forecasts involve uncertainty (Joslyn and Savelli 2010).

However, for climate change, providing explicit uncertainty information may have the opposite effect in a nationally representative sample because there is a sharp division along party lines with conservatives and Republicans being less accepting than liberals and Democrats (Wood and Vedlitz 2007; Zia and Todd 2010; Whitmarsh 2011). For those less accepting of climate change, adding uncertainty information might decrease rather than increase trust. In other words, people may react differently to the same information, based on their prior beliefs. This is predicted by motivated reasoning theory, which asserts that when people hold strong prior beliefs they process new information in a manner that is consistent with, and reinforces, those beliefs (Bolsen and Druckman 2015; Goidel et al. 1997). In fact, there is considerable supporting evidence. For instance, although greater knowledge is associated with more support for climate mitigation among liberals, it is associated with less support among conservatives (Hart et al. 2015). The idea is that as partisans become more factually knowledgeable, or scientifically literate, they are more likely to find reasons to discount information that challenges their existing viewpoints (Bolsen et al. 2015; Kahan 2015). Similarly, reduction of social distance manipulations (news stories describing victims of global warming) that increased support for mitigation policies among Democrats, reduced support among Republicans (Hart and Nisbet 2012). In general, this is known as a boomerang effect: Manipulations that have an effect on one group can have the opposite effect on another group. Therefore, while including uncertainty estimates may increase trust in climate projections among liberals, it may also open the door for motivated reasoning among conservatives. Among conservatives uncertainty estimates may be taken as an indication of lack of consensus, incompetence or of being deliberately misleading. In other words, the same information may be regarded as a fundamentally different kind of uncertainty by this group. As such, it may reduce trust in the source of the information, sometimes referred to as "relational trust," as well as trust in the quality of information, called "calculative trust" (Earle and Siegrist 2006). We test these questions in the two experiments reported here.

The other issue addressed in these experiments is the impact of communication strategies on concern. Even those Americans who believe that the global climate is warming, that is, they trust climate scientists conclusions, remain relatively unconcerned about it. According to recent polls, only $31 \%$ of Americans think immediate action is necessary, only $27 \%$ supported a large-scale effort to reduce global warming, and only $38 \%$ think that dealing with global warming should be a top priority (Bowman et al. 2016). Furthermore, 38\% of Americans are not very or not at all worried about global warming (Leiserowitz et al. 2018).

While there are many possible reasons for the relative lack of concern about climate change (including being supplanted by other more pressing concerns; Riffkin 2014) one possible contributing factor is the way in which climate change is expressed. Climate projections are generally statistical abstractions, such as global average change values, that do not convey information about specific events. Perhaps a global average temperature increase of, for example, $3^{\circ} \mathrm{C}$, seems trivial, making it difficult for people to imagine how climate change would affect their lives. Perhaps if climate communication emphasized outcomes as they might be experienced by individuals, concern would be greater. Although increasing salience of climate communication 
TABLE 1. Climate projections provided to participants in each of the between groups conditions.

\begin{tabular}{|c|c|c|}
\hline & Abstract & Concrete \\
\hline \multirow[t]{2}{*}{ Deterministic } & $\begin{array}{l}\text { Scientists estimate that by the end of the next } \\
\text { century the average yearly temperature will } \\
\text { increase by } 7^{\circ} \mathrm{F} \text { compared to the end of the } \\
\text { last century. }\end{array}$ & $\begin{array}{l}\text { Scientists estimate that by the end of the next } \\
\text { century, heat waves will occur on } 19 \text { more days } \\
\text { per year compared to the end of the last } \\
\text { century. }\end{array}$ \\
\hline & $\begin{array}{l}\text { Scientists estimate that by the end of the next } \\
\text { century the average yearly precipitation will } \\
\text { increase by } 3 \text { inches compared to the end of } \\
\text { the last century. }\end{array}$ & $\begin{array}{l}\text { Scientists estimate that by the end of the next } \\
\text { century, floods will occur on } 5 \text { more days per } \\
\text { year compared to the end of the last century. }\end{array}$ \\
\hline \multirow[t]{2}{*}{ Probabilistic } & $\begin{array}{l}\text { Scientists estimate that by the end of the next } \\
\text { century the average yearly temperature will } \\
\text { increase by } 7^{\circ} \mathrm{F} \text { compared to the end of the } \\
\text { last century, with a } 90 \% \text { chance that the } \\
\text { increase will be between } 4^{\circ} \text { and } 11^{\circ} \mathrm{F} \text {. }\end{array}$ & $\begin{array}{l}\text { Scientists estimate that by the end of the next } \\
\text { century, heat waves will occur on } 19 \text { more days } \\
\text { per year compared to the end of the last } \\
\text { century, with a } 90 \% \text { chance that they will } \\
\text { occur on between } 5 \text { and } 48 \text { more days per year. }\end{array}$ \\
\hline & $\begin{array}{l}\text { Scientists estimate that by the end of the next } \\
\text { century the average yearly precipitation will } \\
\text { increase by } 3 \text { inches compared to the end of } \\
\text { the last century, with a } 90 \% \text { chance that the } \\
\text { increase will be between } 1 \text { and } 5 \text { inches. }\end{array}$ & $\begin{array}{l}\text { Scientists estimate that by the end of the next } \\
\text { century, floods will occur on } 5 \text { more days per } \\
\text { year compared to the end of the last century, } \\
\text { with a } 90 \% \text { chance that they will occur on } \\
\text { between } 2 \text { and } 7 \text { more days per year. }\end{array}$ \\
\hline
\end{tabular}

is a common suggestion (Center for Research on Environmental Decisions 2009), evidence supporting the effectiveness of this strategy is sparse and mixed. For instance there is some evidence of an increase in concern among low numerate participants for the impacts of climate change on polar bears, when combined with numeric as opposed to nonnumeric descriptors (Hart 2013). There is other evidence that descriptions of the impact of sea level rise on coastal communities increases risk perception, although the effects on concern were weak or nonsignificant (Bolsen et al. 2018). In addition there is evidence that the term "global warming" increases concern compared to "climate change" in some cases (Benjamin et al. 2017; Bolsen and Shapiro 2018; Whitmarsh 2009). However, in our own laboratory, attempts to reduce temporal (outcomes within as compared to beyond the participants' lifetime) and spatial distance (local instead of global) did not increase concern (Joslyn and LeClerc 2016). In the experiment we report here, we increase what we will refer to as the "concreteness" of climate information. We ask whether substituting increases in heat waves and floods for global average temperature change and sea level rise impacts concern. Perhaps it will be easier for participants to imagine the effects of heat waves and floods and that, in turn, may increase concern.

We tested these hypotheses in the two experiments described below. To refine the measures, we first used Amazon Mechanical Turk (MTurk), a data-collection domain administered by Amazon. Then we conducted an experiment on a nationally representative sample. In both experiments, we compared what we refer to as abstract expressions (e.g., average temperature change) to concrete expressions (e.g., increase in heat waves). In addition, we compared point estimates for each of these values with $90 \%$ predictive intervals (see Table 1 ). We hypothesized that concrete expressions would increase concern, while $90 \%$ predictive intervals would increase trust. However, each manipulation might interact with political views. Here we use political party affiliation, which is correlated with but not identical to political ideology, a direct measure of the individuals system of values, norms and political preferences ( $\mathrm{Zia}$ and Todd 2010). We anticipated that our predictions would be confirmed among Democrats but not among Republicans. In fact, we anticipated a boomerang effect among Republicans, particularly in the probabilistic condition, leading to decreased trust.

\section{Experiment 1}

In experiment 1 we posted a questionnaire on MTurk between March and May 2016. MTurk is an opt-in platform on which volunteers sign up to complete surveys for incentives. Although MTurk samples tend to differ from probability samples of the public (e.g., MTurkers tend to be more liberal), they have produced results similar to national samples recruited using more conventional procedures (Amir and Rand 2012; Clifford et al. 2015; Gosling and Mason 2015; Horton et al. 2011; Simons and Chabris 2012; Weinberg et al. 2014). Because we anticipated effects due to political party, only those who described themselves as Democrats or Republicans were included. Participants were paid $\$ 0.05$ for their participation in this study. 


\section{a. Method}

\section{1) Procedure}

After providing informed consent, participants read a pair of climate change projections described as being for "a location in the USA." Half of participants received conventional projections for average change in temperature and precipitation by the end of this century compared to the end of the last century, to which we refer as the abstract condition. The other half received concrete expressions describing the increase in heatwave and flood days by the end of this century compared to the end of the last century ${ }^{1}$ (see Table 1). For geographic consistency, the numbers were all for the Puyallup River watershed and the city of Tacoma, Washington, although this information was not made explicit to avoid any biases that could have occurred by specifying the location. All projections were based on phase 5 of the Coupled Model Intercomparison Project (CMIP5). With the exception of precipitation and heavy rainfall events, ${ }^{2}$ projections that were obtained by combining the 10 model projections for each of the 2 greenhouse gas scenarios (high and low), 20 in all, and calculating average, minimum and maximum values. The range between the minimum and maximum was regarded as a $90 \%$ predictive interval and the average became the point estimate. Heat waves were defined as number of days with daily maximum temperature greater than $90^{\circ} \mathrm{F}^{3}$ Similarly, floods were defined as number of days with daily precipitation above the historical 99th percentile event. ${ }^{4}$

Because the calculations for temperature were better theoretically grounded, for all conditions, the temperature (heat waves) projections were presented first and the precipitation (flood) projections were presented second. After reading the first climate projection, participants indicated whether they believed that by the end of this century the observed average value would be

\footnotetext{
${ }^{1}$ In all cases the comparison was between the years 2070-99 and 1970-99.

${ }^{2}$ This was based on representative concentration pathway (RCP) 8.5 and was for October-March precipitation (Warner et al. 2015), although very few heavy rainfall events occur outside of that season. The numbers for precipitation are remarkably similar in the combined and extreme scenario.

${ }^{3}$ Although this threshold varies by location $\left(90^{\circ} \mathrm{F}\right.$ is specific to Tacoma) and "waves" are in fact a certain number of days (e.g., 3) for the sake of simplicity, we omitted these details and described the number of additional "heat-wave days" defined as those that met the $90^{\circ} \mathrm{F}$ criterion for Tacoma.

${ }^{4}$ Granted, many other factors contribute to floods (which are defined differently depending on geographic location); again, however, we chose to simplify.
}

greater, less, or the same compared to the end of the last century. Then, participants provided their own estimate for the increase (or decrease) and a lower and upper bound estimate they would not be surprised to observe. Next participants rated how much they trusted the projection and how concerned they were about it. Both responses were given on a 5-item pulldown menu ranging from "not at all" to "completely" for trust and between "not at all" to "extremely" for concern (see the appendix for exact wording of questions). Then on the next screen, the second climate projection was presented and participants answered the same six questions. Once participants advanced to the subsequent page, they could not change previous answers.

On the next screen, participants were told that the climate information had come from scientists on the Intergovernmental Panel on Climate Change. To assess the potential impact of uncertainty estimates on the perception of scientific consensus, participants were asked to indicate how much agreement about climate change they thought there was among climate scientists. To assess whether uncertainty estimates affected participants opinion of scientists' competence, they answered a question about scientists' expertise and another about scientists understanding of the problem (based on Allum 2007). Answers were indicated on a 6-point pull-down menu ranging between "no agreement" to "complete agreement" for consensus, "none" to "all" for expertise and "not at all" to "completely" for understanding.

Although the trust question described above assessed trust in the climate projection itself (calculative trust), we thought it was important to also assess the impact on relational trust because of its psychological importance to this issue as well as the fact that it may be more sensitive to the manipulations tested here (Earle and Siegrist 2006). To that end, participants were asked how similarly scientists acted and thought to themselves, and to what extent scientists held opinions similar as their own. The answers to all six questions were provided on a 6-point pull-down menu ranging between "not at all" and "identical(ly)." Finally, participants were asked to indicate the extent to which their personal actions could help to mitigate climate change. ${ }^{5}$ At the end, participants answered demographic questions (age, gender, education, political party affiliation; see the appendix) and were debriefed and thanked for their time.

\footnotetext{
${ }^{5}$ No significant effects on this measure of either independent variable were detected in this or experiment 2 so discussion of these analyses are omitted.
} 


\section{2) PARTICIPANTS}

A total of 553 respondents completed the survey and declared a political party affiliation that was either Democrat or Republican. We omitted those who failed our attention check questions. We assumed that the 37 participants who provided estimates that were 4 times the projection provided and/or their lower bound estimate exceeded their upper bound estimate were not paying attention, not taking the task seriously or had misunderstood it. Of the 516 remaining, ${ }^{6}$ the mean age was 35 [standard deviation $(\mathrm{SD})=12$ ], $63 \%$ were female and $65 \%$ were Democrats.

\section{3) DESIGN}

There were two independent variables, Event Type (abstract/concrete) and Projection Format (deterministic/ probabilistic) manipulated between groups in a $2 \times 2$ complete factorial design. Participants were randomly assigned to one of the four resulting conditions.

\section{4) Results}

Prior to conducting the main analyses, Pearson chisquare analyses were conducted to verify that random assignment had resulted in roughly equal proportions of Democrats in each condition. Then, a series of ANOVAs were conducted on the key dependent variables with Projection Format (probabilistic/deterministic), Event Type (concrete/abstract), and Political Party (Democrat/Republican) as the independent variables using an alpha level of 0.05 . All pairwise comparisons were conducted with Statistical Package for the Social Sciences (SPSS) Bonferroni adjustments. ${ }^{7}$ Our main hypotheses were that probabilistic projections would increase trust (main effect) and concrete expressions would increase concern (main effect) although we anticipated smaller or opposite effects among Republicans (interaction between Projection Format or Event Type and Political Party). We expected that Democrats would be higher on all measures than Republicans.

To determine whether probabilistic projections increased trust, we averaged the trust ratings provided by each participant, one for each of the two projections. Participants with probabilistic projections reported marginally significantly higher trust $(M=3.47, \mathrm{SD}=1.11)$ than did participants with deterministic projections $(M=3.32, \mathrm{SD}=1.13), F(1,508)=3.15, p=0.077$ (Cohen's $d=0.16)$. The interaction between Projection Format and Event Type was also marginally significant,

\footnotetext{
${ }^{6}$ The dataset is available upon request from the authors.

${ }^{7}$ SPSS takes the observed (uncorrected) $p$ value and multiplies it by the number of comparisons made.
}

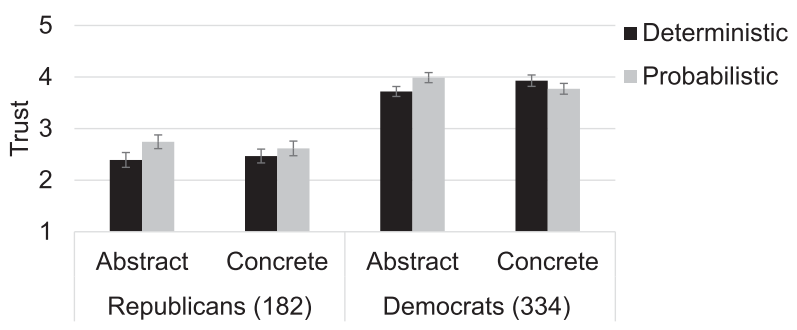

FIG. 1. Mean trust by Political Party, Projection Format, and Event Type in experiment 1 . Error bars indicate the standard error.

$F(1,508)=3.35, p=0.068$. Pairwise comparisons revealed that participants reported significantly higher trust when given probabilistic $(M=3.55, \mathrm{SD}=1.08)$ as opposed to deterministic projections $(M=3.31$, $\mathrm{SD}=1.12), t(273)=2.58, p=0.01($ Cohen's $d=0.23)$ in the abstract condition alone. Not surprisingly, Democrats reported significantly higher trust $(M=3.85$, $\mathrm{SD}=0.85)$ than did Republicans $(M=2.56 \mathrm{SD}=1.08)$, $F(1,508)=227.09, p<0.001$ (Cohen's $d=1.34)$. The interaction between Projection Format and Political Party (that might have indicated a boomerang effect) did not reach significance $F(1,508)=0.017, p=0.90$ (see Fig. 1).

To determine whether concrete expressions increased concern, we examined the average of the two ratings provided by each participant, one for each projection. Contrary to our hypothesis, ratings were virtually identical for the concrete and abstract conditions $(M=3.5)$. Not surprisingly, Democrats $(M=3.87, \mathrm{SD}=0.92)$ reported significantly higher concern than did Republicans $(M=2.41, \mathrm{SD}=1.21), F(1,508)=234.48, p<$ 0.001 (Cohen's $d=1.36$ ).

Thus, although there was no support for the hypothesis that concrete expressions increase concern, there was partial support for the hypothesis that probabilistic expressions increase trust in climate projections in the abstract condition. To investigate whether there were any negative impacts of probabilistic expressions, we next analyzed ratings of scientific agreement and the expertise and understanding of climate scientists.

For ratings of scientific agreement, the main effect of Projection Format did not reach significance. However, there was a marginally significant interaction between Projection Format and Event Type, $F(1,508)=$ $3.15, p=0.077$ (Cohen's $d=0.16$ ). Pairwise comparisons revealed that probabilistic projections led to higher ratings of scientific agreement $(M=4.21, \mathrm{SD}=$ 1.19) than did deterministic projections $(M=3.97$, $\mathrm{SD}=1.33), t(273)=2.02, p=0.043$ (Cohen's $d=0.19$ ) in the abstract condition alone. Not surprisingly, ratings were significantly higher among Democrats $(M=$ 4.47, SD $=1.04)$ than Republicans $(M=3.18$, 


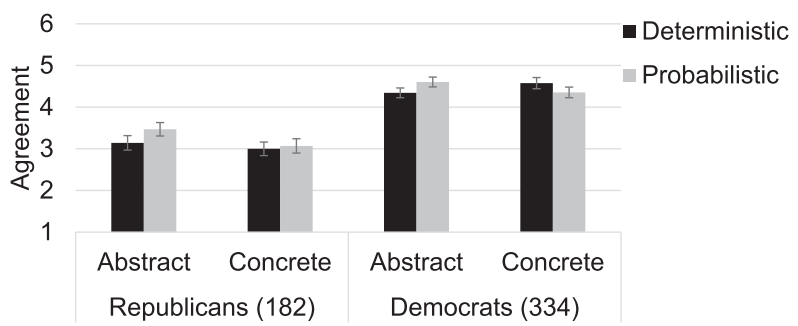

FIG. 2. Mean participant rating of the scientific agreement on climate change by Political Party, Projection Format, and Event Type in experiment 1. Error bars indicate the standard error.

$\mathrm{SD}=1.28), F(1,508)=155.28, p<0.001$ (Cohen's $d=$ 1.11) (see Fig. 2).

Similarly, for ratings of climate scientists' understanding, the interaction between Projection Format and Event Type was significant, $F(1,508)=8.09, p=$ 0.005 . Pairwise comparisons revealed that probabilistic projections led to significantly higher ratings $(M=4.64$, $\mathrm{SD}=1.1)$ than did deterministic projections $(M=4.44$, $\mathrm{SD}=1.26), t(273)=2.12, p=0.035$ (Cohen's $d=0.19)$ in the abstract condition alone. Not surprisingly, Democrats $(M=4.90, \mathrm{SD}=0.92)$ gave higher ratings of scientists' understanding than did Republicans $(M=$ $3.72, \mathrm{SD}=1.31), F(1,508)=147.78, p<0.001$ (Cohen's $d=1.08$ ) (see Fig. 3).

The pattern was repeated for participants' rating of climate scientists' expertise: The interaction between Projection Format and Event Type was significant, $F(1,508)=13.87, p<0.001$. Pairwise comparisons revealed that probabilistic projections led to significantly higher ratings of expertise $(M=4.46, \mathrm{SD}=1.1)$ than did deterministic projections $(M=4.17$, SD $=$ $1.34), t(273)=2.72, p=0.007$ (Cohen's $d=0.24)$ in the abstract condition alone. Again, Democrats $(M=4.66$, $\mathrm{SD}=0.99$ ) gave significantly higher ratings of scientists' expertise than Republicans $(M=3.52$, SD $=$ 1.24), $F(1,508)=13.87, p<0.001$ (Cohen's $d=1.04)$ (see Fig. 4).

The next set of analyses was conducted on the measures of relational trust to determine whether either communication strategy impacted these variables. Here the patterns were weaker but roughly the same as in the previous set of analyses. Participants were significantly more likely to indicate that climate scientists acted like themselves $[t(273)=2.51, p=0.01$ (Cohen's $d=0.22)]$ and marginally more likely to indicate that scientists had opinions like themselves $[t(273)=1.71, p=0.09$ (Cohen's $d=0.26$ )] when given probabilistic as compared to deterministic projections in the abstract condition. Not surprisingly, in all three analysis, Democrats provided higher overall ratings of relational trust than did Republicans [think like me: Democrats $(M=3.94$,

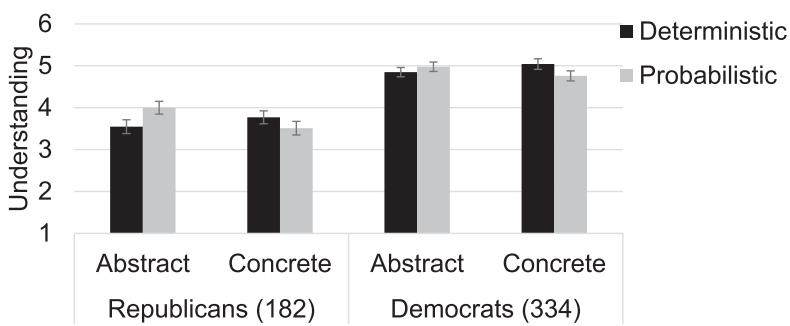

FIG. 3. Mean participant rating of the understanding among climate scientists by Political Party, Projection Format, and Event Type in experiment 1. Error bars indicate the standard error.

$\mathrm{SD}=1.24)$ Republicans $(M=2.43, \mathrm{SD}=1.30)$ $F(1,508)=170.38, p<0.001$ (Cohen's $d=1.16)$; act like me: Democrats $(M=3.96, \mathrm{SD}=1.24)$ Republicans $(M=2.71, \mathrm{SD}=1.25), F(1,508)=120.47, p<0.001$ (Cohen's $d=0.97)$; Opinions like me: Democrats $(M=$ $4.14, \mathrm{SD}=1.21)$ Republicans $(M=2.42, \mathrm{SD}=1.28)$, $F(1,508)=229.93, p<0.001($ Cohen's $d=1.35)]$. No other effects reached significance.

\section{b. Discussion experiment 1}

In experiment 1 we found partial support of the hypothesis that probabilistic projections increase, rather than decrease user trust. However, this effect was seen primarily in the abstract condition. The lack of effect in the concrete condition may have been due to the wider predictive interval for heat waves. Recall that the projection was for an increase of between 5 and 48 more heat-wave days. Perhaps there is a degree of uncertainty above which the previously noted positive effects on trust are no longer observed. In other words, an interval that is too wide may be tantamount to saying, "we don't know." Because the heat-wave projection was always presented first, the effect may have carried over to the narrower interval flood projection, depressing trust for the concrete-probabilistic condition overall. This may be the reason that the increase in trust with probabilistic projections was not observed in the concrete condition in experiment 1.

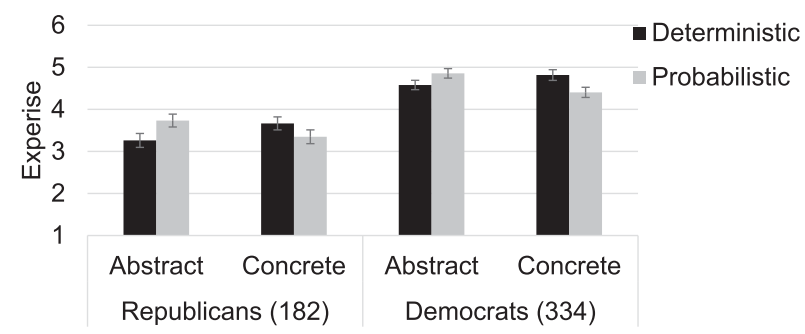

FIG. 4. Mean participant rating of the expertise of climate scientists by Political Party, Projection Format, and Event Type in experiment 1 . Error bars indicate the standard error. 
However, it is interesting to note that the positive effect of probabilistic projections was observed in variables that might have shown negative effects of uncertainty. In the abstract condition, probabilistic expressions increased rather than decreased the perception of scientific consensus as well as the expertise and understanding of climate scientists. In fact, the same positive effect of probabilistic projections was seen in two of the relational trust measures ("act like me" and "opinions like me"). This suggests that the feared negative effects of including uncertainty estimates in climate projections may not be a problem. In fact, probabilistic projections may make scientists seem more rather than less forthright, competent, and reliable.

We did not see the hypothesized increase in concern with concrete as opposed to abstract expressions. However, it is important to note that this was not a nationally representative sample. In fact, it was considerably more liberal overall. It is possible that different effects might be seen when more Republicans are included. There is some evidence that manipulations such as this are particularly strong among conservatives (Feldman and Hart 2018), perhaps because of differences in value structure or perhaps simply because they were lower on key measures to begin with, providing more room to increase. Therefore we conducted experiment 2 on a nationally representative sample.

\section{Experiment 2}

Experiment 2 was conducted to test the effects of probabilistic projections and concrete expressions in a nationally representative sample, obtained by Knowledge Networks, a consumer information research company. The experiment was conducted between the dates of 25 January and 21 March 2017 using an online research panel that was randomly recruited by telephone and mail surveys. Households were provided with access to the Internet and hardware if needed. Thus, the sampling frame included both listed and unlisted numbers, those with and without a landline telephone, and those with and without computer and Internet access. Self-selected volunteers were not accepted.

\section{a. Method}

\section{1) Procedure}

The procedures used in experiment 2 were similar to those used in experiment 1 with the following exceptions. Although the projections were identical, we counterbalanced presentation of the temperature (heat wave) and precipitation (flood). Half of participants saw temperature (heat wave) projections first and half saw precipitation (flood) projections first. The goal was to neutralize some of the effects of the wide predictive interval that accompanied heat waves. Although artificially holding the range constant across conditions is a possible solution, it is important to use valid predictions whenever possible to avoid contradicting intuitions gleaned from extraexperimental exposure. In addition, it allows for the discovery of unpredicted effects, such the possible effect of wide predictive intervals, which may be critical in applied situations.

The questions participants answered after being shown each projection were identical to those used in experiment 1 except, in the interest of time, the relational trust measures were omitted. In addition, for the trust and concern measures pertaining to each projection, we extended the 5-point to a 6-point drop-down scale, so that they would match other measures, with the same anchors as in experiment 1, "not at all" and "completely" for trust and "not at all" and "extremely" for concern.

\section{2) PARTICIPANTS}

A total of 383 Republicans or Democrats participated. ${ }^{8}$ After omitting those who did not pass the attention check questions, there were 332 participants. The median age was 57 (range $=18-92$ ), 53\% were female and $54 \%$ were Democrats.

\section{3) Results}

Prior to running the main analyses, Person's chisquare analyses were conducted to verify that the proportion of Democrats did not differ significantly by condition. Then, as with experiment 1 , we conducted a series of ANOVAs on the key dependent variables with Projection Format (probabilistic/deterministic), Event Type (concrete/abstract), and Political Party (Democrat/ Republican) as the independent variables. ${ }^{9}$

Confirming our hypothesis, participants with probabilistic projections reported significantly higher trust $(M=3.43, \mathrm{SD}=1.43)$ than did those with deterministic

\footnotetext{
${ }^{8}$ These data were collected as part of a larger study but only the responses of participant who clearly identified with one or the other of the two major political parties were included here.

${ }^{9}$ Trust and concern ratings were averaged across the two provided (one for each projection) unless a participant failed to respond to one (this was true of 3 participants for each measure). In that case the value of the other was used. If participants failed to respond to either or to any of the other questions for which there was a single response, they were omitted from that analysis. Therefore, the degrees of freedom vary slightly in the analysis reported below.
} 


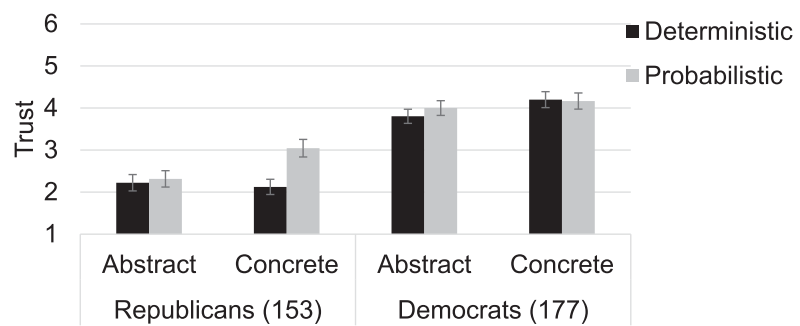

FIG. 5. Mean trust by Political Party, Projection Format, and Event Type in experiment 2. Error bars indicate the standard error.

projections $(M=3.12, \mathrm{SD}=1.49), F(1,322)=4.86$, $p=0.028$ (Cohen's $d=0.25$ ). There was also an unpredicted effect of Event Type such that those informed of concrete events reported higher trust $(M=$ $3.36, \mathrm{SD}=1.48)$ than those informed of abstract events $(M=3.19, \mathrm{SD}=1.45), F(1,322)=5.02, p=0.026$ (Cohen's $d=0.25$ ). Democrats reported significantly higher trust $(M=4.03, \mathrm{SD}=1.22)$ than did Republicans $(M=2.4, \mathrm{SD}=1.22), F(1,322)=146.93, p<$ 0.001 (Cohen's $d=1.35$ ). The three-way interaction was also significant, $F(1,322)=3.94, p=0.048$. In the concrete condition, the difference in trust between probabilistic $(M=3.05, \mathrm{SD}=1.38)$ and deterministic projections $(M=2.13, \mathrm{SD}=1.14)$ was greater for Republicans than for Democrats (probabilistic: $M=$ 4.17, $\mathrm{SD}=1.14$; deterministic: $M=4.20, \mathrm{SD}=1.11$ ) Only the pairwise comparison for Republicans reached significance $[t(75)=3.33, p=0.001$, Cohen's $d=0.74]$ (see Fig. 5).

In line with our hypothesis, Republicans reported greater concern for concrete events $(M=2.68, \mathrm{SD}=$ 1.57) than for abstract events $(M=1.97, \mathrm{SD}=1.02)$, $t(70)=2.25, p=0.025$ (Cohen's $d=0.54$ ) in the probabilistic condition, although the three-way interaction did not reach significance, $F(1,323)=2.35$, $p=0.13$. Nor was the predicted main effect for Event Type, $F(1,323)=2.52, p=0.11$ (Cohen's $d=0.18$ ) significant. There was a significant effect of Political Party such that Democrats reported greater concern overall $(M=3.99, \mathrm{SD}=1.39)$ than did Republicans $(M=2.12, \mathrm{SD}=1.25), F(1,323)=160.24, p<0.001$ (Cohen's $d=1.41)$. The main effect of Projection Format, $F(1,323)=2.09, p=0.15$ (Cohen's $d=0.16)$ was not significant (see Fig. 6).

These results provide support for the hypothesis that including probabilistic uncertainty expressions increases rather than decreases trust. Interestingly among Republicans, not well represented in experiment 1 , this effect was particularly strong in the concrete condition. This effect appeared to carry through into concern ratings, suggesting that the combination of concrete

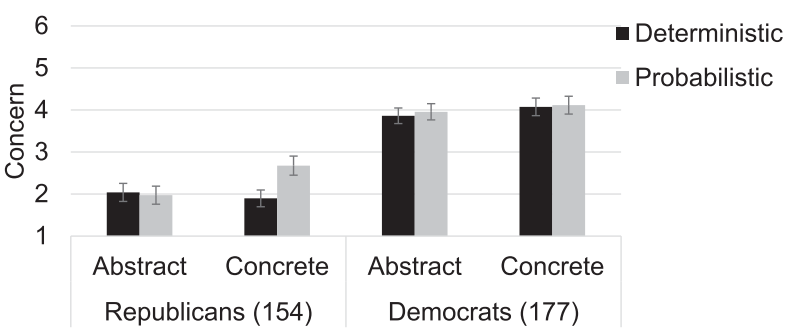

FIG. 6. Mean concern by Political Party, Projection Format, and Event Type in experiment 2. Error bars indicate the standard error.

probabilistic expressions was particularly effective for this group.

In the analyses of participants' attitudes toward climate scientists, reported next, the effects were also largely among Republicans. Among Republicans in the concrete condition, probabilistic projections led to significantly higher ratings of scientific agreement $(M=3.06, \mathrm{SD}=1.23)$ than deterministic projections $(M=2.55, \mathrm{SD}=1.10), t(76)=1.94, p=0.05$ (Cohen's $d=0.21$ ) (see Fig. 7). It is interesting to note that the effect reversed among Democrats in the concrete condition. Probabilistic projections led to lower ratings of agreement $(M=4.10, \mathrm{SD}=1.29)$ than deterministic projections $(M=4.40, \mathrm{SD}=1.17)$, although the difference failed to reach significance, $t(77)=-1.13, p=$ 0.26 (Cohen's $d=-0.24$ ). There was, of course, a main effect of political party with Democrats providing higher ratings of scientific agreement $(M=4.19, \mathrm{SD}=1.20)$ than Republicans $(M=2.68, \mathrm{SD}=1.13), F(1,323)=$ $137.29, p<0.001$ (Cohen's $d=1.3$ ). No other main effects or interactions reached significance.

Similarly, for ratings of climate scientists' understanding, there was a significant interaction between Political Party and Projection Format $F(1,321)=3.87$, $p=0.05$ (Cohen's $d=0.22$ ) (see Fig. 8). For Republicans, probabilistic expressions led to higher ratings of scientists understanding, whereas for Democrats, deterministic projections led to high ratings. However, the only pairwise comparison to reach significance was

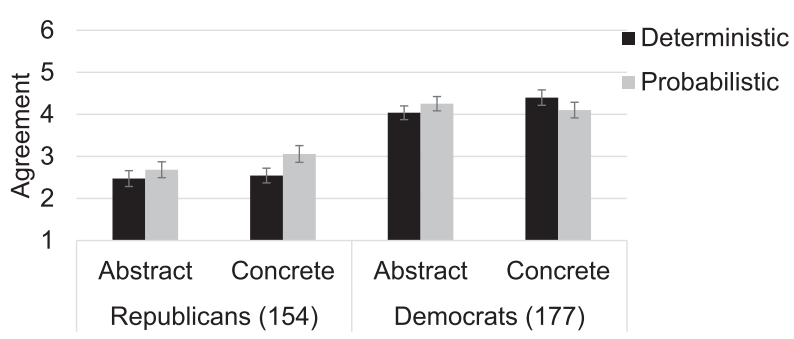

FIG. 7. Mean participant rating of the Scientific Agreement on Climate Change by Political Party, Projection Format, and Event Type experiment 2. Error bars indicate the standard error. 


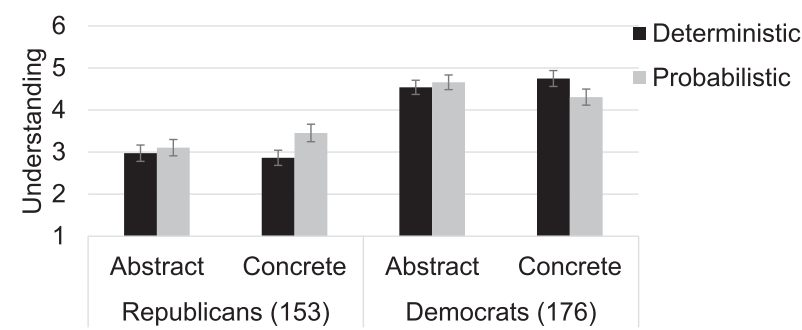

FIG. 8. Mean participant rating of the Understanding among Climate Scientists by Political Party, Projection Format, and Event Type in experiment 2. Error bars indicate the standard error.

for Republicans in the concrete condition: Ratings of scientists' understanding were significantly higher in the probabilistic $(M=3.45, \mathrm{SD}=1.35)$ than in the deterministic condition $(M=2.86, \mathrm{SD}=1.42), t(75)=$ $2.15, p=0.033$ (Cohen's $d=0.42$ ). The effect reversed among Democrats in the concrete condition (deterministic: $M=4.75, \mathrm{SD}=1.15$; probabilistic: $M=4.31$, $\mathrm{SD}=1.03)$, although the difference failed to reach significance, $t(77)=-1.64, p=0.101$ (Cohen's $d=-0.4)$. There was, of course, a main effect of political party such that Democrats rated scientific understanding higher $(M=4.57, \mathrm{SD}=1.08)$ than did Republicans $(M=3.08, \mathrm{SD}=1.32), F(1,321)=121.63, p<0.001$ (Cohen's $d=1.23$ ).

Although the pattern was similar for participants' rating of climate scientists' expertise (see Fig. 9) the only difference that reached significance was the main effect indicating that Democrats thought climate scientists had greater expertise $(M=4.46, \mathrm{SD}=1.1)$ than did Republicans $(M=2.88, \mathrm{SD}=1.08), F(1,322)=169.72$, $p<0.001$ (Cohen's $d=1.45$ ).

\section{b. Discussion experiment 2}

In experiment 2, with a nationally representative sample, there was convincing support for the hypothesis that uncertainty information increases rather than decreases trust in climate predictions. Because these effects were particularly strong among Republicans, it may be that the main effect failed to reach significance in experiment 1 because the sample was too liberal, leaving little room for increase in trust, a ceiling effect.

Moreover, in experiment 1 because the effect of probabilistic projections on trust only reached significance in the abstract condition, we speculated that the wide predictive interval for heat waves in the concrete condition may have been a problem. In experiment 2 , however, concrete expressions led to greater trust overall than did abstract expressions, despite the fact that the same wide heat-wave interval was used. This may have been due in part to the fact that presentation order was counterbalanced (heat waves were presented

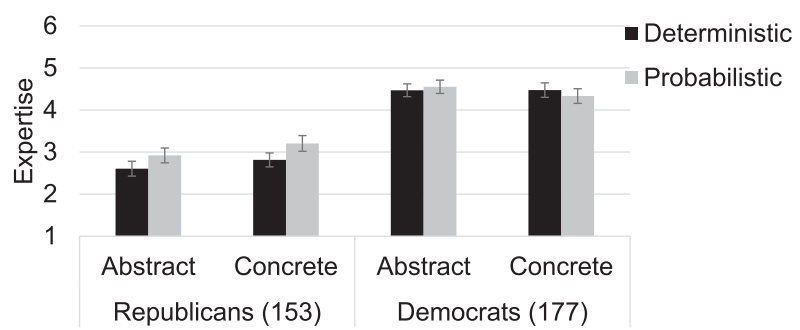

FIG. 9. Mean participant rating of the Expertise of Climate Scientists by Political Party, Projection Format, and Event Type. Error bars indicate the standard error.

first for only half of participants in experiment 2 , rather than for the full sample as in experiment 1) muting the negative effects of the wide heat-wave interval on mean trust.

However, as the post hoc analyses revealed, the positive effects of the concrete-probabilistic combination were especially strong among Republicans, suggesting that some of the difference with experiment 1 may be due to the difference in the sample characteristics. Indeed similar positive effects among Republicans were observed for concern, scientific agreement (our measure of perceived consensus), and scientists understanding in experiment 2. This suggests that the probabilisticconcrete combination is particularly effective for this group that was not well represented in experiment 1 .

\section{Conclusions}

The goal of the research reported here was to identify climate communication strategies that increase either trust in or concern about climate change information. The results suggest that including probabilistic uncertainty estimates will serve to increase rather than decrease trust in climate change projections provided to the general public. In experiment 1 , the increase reached significance in the abstract condition, and in experiment 2, it reached significance overall. It is likely that probabilistic expressions increase trust because even nonexperts understand that predictions such as these involve uncertainty (Joslyn and Savelli 2010). When predictions exclude uncertainty information, they seem less plausible because people know that such outcomes cannot be predicted with the precision implied by deterministic expressions. Therefore communication that acknowledges uncertainty seems more honest and more accurate.

There was some fear that admitting uncertainty would boomerang among Republicans who tend to be less trusting of climate change information to begin with (Wood and Vedlitz 2007; Zia and Todd 2010; Whitmarsh 2011). Motivated reasoning can cause new 
information to be evaluated in a manner that reinforces strongly held prior beliefs (Bolsen and Druckman 2015; Goidel et al. 1997). Here we hypothesized that uncertainty information might decrease perceptions of scientific consensus and the competence of climate scientists. In fact, exactly the opposite occurred. Probabilistic expressions increased ratings of scientific agreement, scientists' understanding and scientists' expertise among the entire sample in the abstract condition in experiment 1 and among Republicans in the concrete condition in experiment 2 . Thus, the inclusion of probabilistic uncertainty estimates seems to have conveyed the idea that the range of values is a function of the prediction process rather than an indication of disagreement or incompetence. It is important to note that in no conditions and among neither group did uncertainty information decrease either trust (including relational trust measured in experiment 1) or perceptions of scientific consensus or scientists' competence.

In fact, the combination of concrete-probabilistic expressions was particularly effective among Republicans. It may be that the concrete expression enhanced processing of the uncertainty information by translating it into an "ensemble of experiences" (see Marx et al. 2007 for a more complete explanation). In other words, it might have been easier to grasp the full range of impacts when described as heat waves and floods, allowing participants to fully appreciate the uncertainty.

Moreover, among Republicans concrete-probabilistic expressions increased not only those variables described above, but also concern in experiment 2 . Recall that we predicted that concrete expressions would increase concern overall because it would be easier to imagine the consequences of climate change for the individual. Although this effect did not reach significance among Democrats, whose concern ratings were already past the midpoint on the scale, it was significant among Republicans in the concrete condition in experiment 2. This may have been due to the fact that the trust inspired by acknowledging uncertainty allowed participants to fully consider the implications of climate change that were particularly accessible because of the concrete nature of the expression. Alternatively, some Republicans in the deterministic condition, intuitively aware of the underlying uncertainty, may have mistakenly thought that scientists, in an effort to persuade the public, had chosen the upper bound of the distribution as the point estimate. For that reason, concern in the deterministic condition might have been depressed, compared to the probabilistic condition in which the actual much higher upper bounds were provided. Regardless of the mechanism, it may well be that concrete-probabilistic expressions are particularly effective for reaching this subgroup, leading to strong positive (nonboomerang) effects. Indeed, similar effects specific to this subgroup have been reported in other studies (Bolsen et al. 2018, 2019; Feldman and Hart 2018; Whitmarsh and Corner 2017).

There were some key differences in the results of the experiment 1 and experiment 2 that may have had to do with the more liberal MTurk sample used in experiment 1 and point to an important issue that requires more research. In particular, the advantage for probabilistic projections was only seen in the abstract condition in experiment 1 suggesting that wide heat-wave interval may have depressed the positive effect of probabilistic expressions in the concrete condition for this sample. Indeed there were some hints of a similar effect in experiment 2 in which Democrats reported slightly lower agreement and scientific understanding in the concrete-probabilistic condition, although neither effect reached significance. Granted the evidence here is only suggestive, but it may be that a particularly wide predictive interval attenuates or even reverses the positive effects of probabilistic expressions at the higher end of the trust-related measures used here. This is clearly an important direction for future research to explore.

Perhaps the strongest effects, across both experiments were those due to political party. Democrats trusted climate projections more, had greater concern about them, perceived greater consensus among climate scientists as well greater understanding and expertise among climate scientists. In experiment 1 (where these questions were asked), Democrats indicated that climate scientists, thought, acted, and had opinions more like themselves than did Republicans. This adds to the growing literature suggesting the highly politicized nature of this issue (Lorenzoni et al. 2007; Whitmarsh 2011).

Nonetheless, the positive effects of the concreteprobabilistic expression observed among Republican participants in these experiments suggest that climate communication can make a difference despite the division. Importantly, this research suggests that climate communication aimed at nonexpert audiences in general, should include an estimate of predictive uncertainty, such as the $90 \%$ intervals tested here. People understand that prediction involves uncertainty and they find projections that acknowledge uncertainty more plausible.

Acknowledgments. Funding for the research described here was provided by the National Science Foundation (NSF) Award SES-1430781 AM002. We thank Giullaume Mauger of the Climate Impact Group at the University 
of Washington for his assistance in calculating the climate projections.

\section{APPENDIX}

\section{Questionnaire}

The following are questions that participants in abstract probabilistic condition would be given.

Please read the following climate predictions for a location in the USA and answer the questions thoughtfully. Scientists estimate that by the end of the next century the average yearly temperature will increase by $7^{\circ} \mathrm{F}$ compared to the end of the last century, with a $90 \%$ chance that the increase will be between $4^{\circ}$ and $11^{\circ} \mathrm{F}$.

1) Please indicate whether you believe that by the end of the next century the average yearly temperature will be greater, less, or the same, compared to the end of the last century.

_Greater

_Less

_The same

If participants answered Greater they will be exposed to the following question:

2a) I think that by the end of the next century the average yearly temperature will increase by

${ }^{\circ} \mathrm{F}$ compared to the end of the last century.

If participants answered Less they will be exposed to the following question:

2b) I think that by the end of the next century the average yearly temperature will decrease by

${ }^{\circ} \mathrm{F}$ compared to the end of the last century?

All participants answer the following questions:

3) I would not be surprised if, by the end of the next century, the change in average yearly temperature was as little as ${ }^{\circ} \mathrm{F}$.

4) I would not be surprised if, by the end of the next century, the change in average yearly temperature was as great as ${ }^{\circ} \mathrm{F}$.

5) How much do you trust scientists' estimate that, by the end of the next century, the average yearly temperature will increase by $7^{\circ} \mathrm{F}$ compared to the end of the last century, with a $90 \%$ chance that the increase will be between $4^{\circ}$ and $11^{\circ} \mathrm{F}$ ?

1) Trust: Not at all

2) Trust: A little

3) Trust: Somewhat

4) Trust: Quite a bit

5) Trust: Extremely

6) How concerned are you about scientists' estimate that, by the end of the next century, the average yearly temperature will increase by $7^{\circ} \mathrm{F}$ compared to the end of the last century, with a $90 \%$ chance that the increase will be between $4^{\circ}$ and $11^{\circ} \mathrm{F}$ ?

1) Concern: Not at all

2) Concern: A little

3) Concern: Somewhat

4) Concern: Quite a bit

5) Concern: Extremely

Scientists estimate that by the end of the next century the average yearly precipitation will increase by 3 inches compared to the end of the last century, with a $90 \%$ chance that the increase will be between 1 and 5 inches.

7) Please indicate whether you believe that by the end of the next century, average yearly precipitation will be greater, less or the same compared the end of the last century.

-Greater

_Less

_The same

If participants answered "greater" they were exposed to the following question:

8a) I think that by the end of the next century the average yearly precipitation will increase inches compared to the end of the last century.

If participants answered "less" they were exposed to the following question:

8b) I think that by the end of the next century the average yearly precipitation will decrease by inches compared to the end of the last century.

9) I would not be surprised if, by the end of the next century, the change in average yearly precipitation was as little as inches.

10) I would not be surprised if, by the end of the next century, the change in average yearly precipitation by the end of the next century was as great as ${ }^{\circ} \mathrm{F}$.

11) How much do you trust scientists' estimate that by the end of the next century, average yearly precipitation will increase by 3 inches compared to the end of the last century, with a $90 \%$ chance that the increase will be between 1 and 5 inches."

1) Trust: Not at all

2) Trust: A little

3) Trust: Somewhat

4) Trust: Quite a bit

5) Trust: Extremely

12) How concerned are you about scientists' estimate that by the end of the next century, average yearly precipitation will increase by 3 inches compared to the end of the last century, with a $90 \%$ chance that the increase will be between 1 and 5 inches? 

1) Concern: Not at all
2) Concern: A little
3) Concern: Somewhat
4) Concern: Quite a bit
5) Concern: Extremely

The following questions are presented on the next page and participants cannot go back and change answers on previous pages

The climate predictions presented above were based on a report by the Intergovernmental Panel on Climate Change (IPCC).

13) How much agreement is there among scientists about climate change?

1-No agreement

2-A little

3-Some

4-Quite a bit

5-Very much

6-Complete agreement

14) Thinking about the scientists contributing to the IPCC report, how much of the expertise necessary expertise do they have to make climate predictions?

1-None

2-A little

3-Some

4-Quite a bit

5-Very much

6-All

15) How well do scientists contributing to the IPCC report understand the issues relevant to climate change?

1 -Not at all

2-A little

3-Some

4-Quite a bit

5-Very much

6-Completely

16) To what degree do scientists contributing to the IPCC report act the same as you would?

1 -Not at all

2-A little

3-Somewhat

4-Quite a bit

5-Very much

6-Identically

17) To what degree do scientists contributing to the IPCC report think like you do?

1 -Not at all

2-A little

3-Somewhat

4-Quite a bit

5-Very much

6-Identically
18) To what degree are the opinions of scientists contributing to the IPCC report the same as yours?

$1-$ Not at all

2-A little

3-Somewhat

4-Quite a bit

5-Very much

6-Identical

19) How much can your personal actions help to mitigate climate change?

$1-$ Not at all

2-A little

3-Some

4-Quite a bit

5-Very much

6-Completely

Please enter your age.

Please select your gender.

Please enter your zip code.

Please provide the name of the city and state you are currently answering these questions.

Please select which of the following best describes your highest achieved education level.

(1) High school diploma or less

(2) Technical school/some college

(3) College degree

(4) Postgraduate work or degree

(5) Other

Please select how much knowledge of atmospheric and climate science you have.

(1) none

(2) a little

(3) some

(4) a lot

Please select your political party affiliation.

(1) Republican

(2) Democrat

(3) Independent

(4) Unaffiliated

(5) Other

\section{REFERENCES}

Allum, N., 2007: An empirical test of competing theories of hazardrelated trust: The case of GM food. Risk Anal., 27, 935-946, https://doi.org/10.1111/j.1539-6924.2007.00933.x.

Amir, O., and D. G. Rand, 2012: Economic games on the internet: The effect of \$1 stakes. PLOS ONE, 7, e31461, https://doi.org/ 10.1371/journal.pone.0031461.

Anderegg, W. R., J. W. Prall, J. Harold, and S. H. Schneider, 2010: Expert credibility in climate change. Proc. Natl. Acad. Sci. USA, 107, 12 107-12 109, https://doi.org/10.1073/ pnas. 1003187107.

Benjamin, D. M., and D. V. Budescu, 2018: The role of type and source of uncertainty on the processing of climate models 
projections. Front. Psychol., 9, 403, https://doi.org/10.3389/ fpsyg.2018.00403.

- H. H. Por, and D. Budescu, 2017: Climate change versus global warming: Who is susceptible to the framing of climate change? Environ. Behav., 49, 745-770, https://doi.org/10.1177/ 0013916516664382.

Bierbaum, R., and Coauthors, 2013: A comprehensive review of climate adaptation in the United States: More than before, but less than needed. Mitig. Adapt. Strategies Global Change, 18, 361-406, https://doi.org/10.1007/s11027-012-9423-1.

Bolsen, T., and J. N. Druckman, 2015: Counteracting the politicization of science. J. Commun., 65, 745-769, https://doi.org/ 10.1111/jcom.12171.

— , and M. A. Shapiro, 2018: Strategic framing and persuasive messaging to influence climate change perceptions and decisions. Oxford Research Encyclopedia of Climate Science, doi:10.1093/acrefore/9780190228620.013.385.

_ - J. N. Druckman, and F. L. Cook, 2015: Citizens', scientists', and policy advisors' beliefs about global warming. Ann. Amer. Acad. Polit. Soc. Sci., 658, 271-295, https://doi.org/10.1177/ 0002716214558393.

—, J. Kingsland, and R. Palm, 2018: The impact of frames highlighting coastal flooding in the USA on climate change beliefs. Climatic Change, 147, 359-368, https://doi.org/10.1007/ s10584-018-2143-0.

_- , R. Palm, and J. T. Kingsland, 2019: Counteracting climate science politicization with effective frames and imagery. Sci. Commun., 41, 147-171, https://doi.org/10.1177/ 1075547019834565.

Bowman, K., E. O'Neil, and H. Sims, 2016: Polls on the environment, energy, global warming and nuclear power. American Enterprise Institute for Public Policy Research, 143 pp., http://www.aei.org/wp-content/uploads/2013/04/-aeipublic-opinion-study-environment-and-energy-april-2013 143748605014.pdf.

Center for Research on Environmental Decisions, 2009: The psychology of climate change communication: A guide for scientists, journalists, educators, political aides, and the interested public. CRED, 54 pp., http://guide.cred.columbia.edu/pdfs/ CREDguide_full-res.pdf.

Clifford, S., R. M. Jewell, and P. D. Wagonner, 2015: Are samples drawn from Mechanical Turk valid for research on political ideology? Res. Polit., 2, https://doi.org/10.1177/ 2053168015622072.

Cook, J., and Coauthors, 2013: Quantifying the consensus on anthropogenic global warming in the scientific literature. Environ. Res. Lett., 8, 024024, https://doi.org/10.1088/1748-9326/ 8/2/024024.

Ding, D., E. W. Maibach, X. Zhao, C. Roser-Renouf, and A. Leiserowitz, 2011: Support for climate policy and societal action are linked to perceptions of scientific agreement. Nat. Climate Change, 1, 462-466, https://doi.org/ 10.1038/nclimate1295.

Earle, T. C., and M. Siegrist, 2006: Morality information, performance information, and the distinction between trust and confidence 1. J. Appl. Soc. Psychol., 36, 383-416, https:// doi.org/10.1111/j.0021-9029.2006.00012.x.

Feldman, L., and P. S. Hart, 2018: Is there any hope? How climate change news imagery and text influence audience emotions and support for climate mitigation policies. Risk Anal., 38, 585-602, https://doi.org/10.1111/risa.12868.

Freudenburg, W. R., and V. Muselli, 2010: Global warming estimates, media expectations, and the asymmetry of scientific challenge. Global Environ. Change, 20, 483-491, https:// doi.org/10.1016/j.gloenvcha.2010.04.003.

Goidel, R. K., T. G. Shields, and M. Peffley, 1997: Priming theory and RAS models: Toward an integrated perspective of media influence. Amer. Polit. Res., 25, 287-318, https://doi.org/ 10.1177/1532673X9702500303.

Gosling, S. D., and W. Mason, 2015: Internet research in psychology. Annu. Rev. Psychol., 66, 877-902, https://doi.org/10.1146/ annurev-psych-010814-015321.

Grounds, M., and S. Joslyn, 2018: Communicating weather forecast uncertainty: Do individual differences matter? J. Exp. Psychol. Appl., 24, 18-33, https://doi.org/10.1037/xap0000165.

,$- \ldots$, and K. Otsuka, 2017: Probabilistic interval forecasts: An individual differences approach to understanding forecast communication. Adv. Meteor., 2017, 3932565, https://doi.org/ 10.1155/2017/3932565.

Hart, P. S., 2013: The role of numeracy in moderating the influence of statistics in climate change messages. Public Understanding Sci., 22, 785-798, https://doi.org/10.1177/0963662513482268. , and E. C. Nisbet, 2012: Boomerang effects in science communication: How motivated reasoning and identity cues amplify opinion polarization about climate mitigation policies. Commun. Res., 39, 701-723, https://doi.org/10.1177/ 0093650211416646.

,-- , and T. A. Myers, 2015: Public attention to science and political news and support for climate change mitigation. Nat. Climate Change, 5, 541, https://doi.org/10.1038/nclimate2577.

Horton, J. J., D. G. Rand, and R. J. Zeckhauser, 2011: The online laboratory: Conducting experiments in a real labor market. Exp. Econ., 14, 399-425, https://doi.org/10.1007/ s10683-011-9273-9.

Johnson, B. B., 2003: Further notes on public response to uncertainty in risks and science. Risk Anal., 23, 781-789, https:// doi.org/10.1111/1539-6924.00355.

_ assessment: Initial studies of its effects on risk perception and trust. Risk Anal., 15, 485-494, https://doi.org/10.1111/ j.1539-6924.1995.tb00341.x.

_ , and _ 1998: Lay views on uncertainty in environmental health risk assessment. J. Risk Res., 1, 261-279, https://doi.org/ 10.1080/136698798377042.

Joslyn, S., and S. Savelli, 2010: Communicating forecast uncertainty: Public perception of weather forecast uncertainty. Meteor. Appl., 17, 180-195, https://doi.org/10.1002/met.190. , and J. E. LeClerc, 2012: Uncertainty forecasts improve weather-related decisions and attenuate the effects of forecast error. J. Exp. Psychol. Appl., 18, 126-140, https://doi.org/ 10.1037/a0025185.

$\longrightarrow$, and - 2016: Climate projections and uncertainty communication. Top. Cognit. Sci., 8, 222-241, https://doi.org/ 10.1111/tops.12177.

Kahan, D. M., 2015: Climate science communication and the measurement problem. Polit. Psychol., 36, 1-43, https://doi.org/ 10.1111/pops.12244.

Leiserowitz, A., E. Maibach, C. Roser-Renouf, G. Feinberg, and P. Howe, 2013: Americans' actions to limit global warming in April 2013. Yale University and George Mason University, Yale Project on Climate Change Communication, 107 pp., https://climatecommunication.yale.edu/wp-content/uploads/ 2016/02/2013_06_Americans\%E2\%80\%99-Actions-to-LimitGlobal-Warming-April-2013.pdf.

_ - - - - , S. Rosenthal, M. Cutler, and J. Kotcher, 2018: Climate change in the American mind: March 2018. 
Yale University and George Mason University, Yale Program on Climate Change Communication, 55 pp., https:// climatecommunication.yale.edu/wp-content/uploads/2018/04/ Climate-Change-American-Mind-March-2018-1.pdf.

Lewandowsky, S., G. E. Gignac, and S. Vaughan, 2013: The pivotal role of perceived scientific consensus in acceptance of science. Nat. Climate Change, 3, 399-404, https://doi.org/ 10.1038/nclimate1720.

Lorenzoni, I., S. Nicholson-Cole, and L. Whitmarsh, 2007: Barriers perceived to engaging with climate change among the UK public and their policy implications. Global Environ. Change, 17, 445-459, https://doi.org/10.1016/j.gloenvcha.2007.01.004.

Marlon, J. R., A. Leiserowitz, and G. Feinberg, 2013: Scientific and public perspectives on climate change. Yale Project on Climate Change Communication, http://environment.yale.edu/ climate-communication/article/scientific-and-public-perspectiveson-climate-change.

Marx, S., E. Weber, B. Orlove, A. Leiserowitz, D. Krantz, C. Roncoli, and J. Phillips, 2007: Communication and mental processes: Experiential and analytic processing of uncertain climate information. Global Environ. Change, 17, 47-58, https://doi.org/10.1016/j.gloenvcha.2006.10.004.

Moser, S. C., 2010: Communicating climate change: History, challenges, process and future directions. Wiley Interdiscip. Rev.: Climate Change, 1, 31-53, https://doi.org/10.1002/wcc.11.

National Research Council, 2011: Informing an Effective Response to Climate Change. National Academies Press, 346 pp., https:// doi.org/10.17226/12784.

Nisbet, M., and E. Markowitz, 2016: Strategic science communication on environmental issues. American Association for the Advancement of Science, 20 pp., https:// www.aaas.org/sites/default/files/content_files/NisbetMarkowitz_ StrategicSciCommOnEnvironmentalIssues_WhitePaper.pdf.

Oreskes, N., and E. M. Conway, 2010: Defeating the merchants of doubt. Nature, 465, 686, https://doi.org/10.1038/465686a.

Rabinovich, A., and T. A. Morton, 2012: Unquestioned answers or unanswered questions: Beliefs about science guide responses to uncertainty in climate change risk communication. Risk Anal., 32, 992-1002, https://doi.org/10.1111/j.15396924.2012.01771.x.

Riffkin, R., 2014: Climate change not a top worry in US: US concerns with the quality of the environment dropped in 2014. Gallup, accessed 12 March 2018, https://news.gallup.com/poll/ 167843/climate-change-not-top-worry.aspx.
Savelli, S., and S. Joslyn, 2013: The advantages of predictive interval forecasts for non-expert users and the impact of visualizations. Appl. Cognit. Psychol., 27, 527-541, https:// doi.org/10.1002/acp.2932.

Simons, D. J., and C. F. Chabris, 2012: Common (mis) beliefs about memory: A replication and comparison of telephone and Mechanical Turk survey methods. PLOS ONE, 7, e51876, https://doi.org/10.1371/journal.pone.0051876.

van der Linden, S. L., A. A. Leiserowitz, G. D. Feinberg, and E. W. Maibach, 2015: The scientific consensus on climate change as a gateway belief: Experimental evidence. PLOS ONE, 10, e0118489, https://doi.org/10.1371/journal.pone.0118489.

Warner, M. D., C. F. Mass, and E. P. Salathé Jr., 2015: Changes in winter atmospheric rivers along the North American West Coast in CMIP5 climate models. J. Hydrometeor., 16, 118-128, https://doi.org/10.1175/JHM-D-14-0080.1.

Weinberg, J. D., J. Freese, and D. McElhattan, 2014: Comparing data characteristics and results of an online factorial survey between a population-based and a crowdsourcerecruited sample. Sociol. Sci., 1, 292-310, https://doi.org/ 10.15195/v1.a19.

Whitmarsh, L., 2009: Behavioural responses to climate change: Asymmetry of intentions and impacts. J. Environ. Psychol., 29, 13-23, https://doi.org/10.1016/j.jenvp.2008.05.003.

_- 2011: Scepticism and uncertainty about climate change: Dimensions, determinants and change over time. Global Environ. Change, 21, 690-700, https://doi.org/10.1016/ j.gloenvcha.2011.01.016.

— , and A. Corner, 2017: Tools for a new climate conversation: A mixed-methods study of language for public engagement across the political spectrum. Global Environ. Change, 42, 122-135, https://doi.org/10.1016/j.gloenvcha.2016.12.008.

Wood, B. D., and A. Vedlitz, 2007: Issue definition, information processing, and the politics of global warming. Amer. J. Polit. Sci., 51, 552-568, https://doi.org/10.1111/j.1540-5907.2007.00267.x.

Wuebbles, D. J., and Coauthors, 2017: Executive summary. Climate Science Special Report: Fourth National Climate Assessment, Vol. I, D. J. Wuebbles et al. Eds., U.S. Global Change Research Program, 12-34.

Zia, A., and A. M. Todd, 2010: Evaluating the effects of ideology on public understanding of climate change science: How to improve communication across ideological divides? Public Understanding Sci., 19, 743-761, https://doi.org/10.1177/ 0963662509357871. 